\title{
The Emergence and Growth of Evolutionary Art - 1980-1993
}

\author{
Nicholas Lambert, William Latham, Frederic Fol Leymarie
}

\section{A B S T R ACT}

One of the most interesting -if frustrating-aspects of charting the history of computer art is trying to understand the intersections of specific technologies and artistic experimentation. It is rarely as clearcut as a simple linear influence of one to the other, partly because artists are able to envision all kinds of possibilities that technology might enable them to realize in some kind of form, but as they do so, the technology is itself shaped, especially in terms of how it is perceived by others. Do artists find a way to give technologies an aesthetic outlet, or do some technologies possess-or facilitate-a characteristic aesthetic that finds its expression through specific artists? Certainly, in the history of computer art it would seem that particular aesthetics, technologies, and artists are closely intertwined in certain periods. This intertwining of art, technology, and ideas stolen from the natural world has never been so arguably merged as the period in the history of computer art from 1980 to 1993 . We take as the defining start of this period the initial work of Mandelbrot on fractals that became known as the Mandelbrot set and led to his famous illustrated art-science book The Fractal Geometry of Nature. In 1993, this first highly creative period in evolutionary computer art came to an end with major publications by pioneers Karl Sims, Stephen Todd, and William Latham.

\section{Artist-Researchers and New Graphics Technologies in the 1980s}

Although the emergence of personal computers by 1980 enabled a new generation of artists to start experimenting with digital images, especially due to the Apple Mac, Commodore Amiga, and Atari ST, in 1984-85, as advanced graphics and sound capabilities became available, there were those who continued to be closely associated with academic and corporate research centres. The Xerox PARC model was undoubtedly influential in providing a template for research collaborations, and IBM in particular supported some interesting developments. In such environments, artists could leverage the power of multiple networked computers, use software that was still under development, and utilize video displays and printers that were far more advanced than those available elsewhere.

The emergence of computer graphics as a major aspect of commercial TV and film production, in addition to its use for scientific visualizations and military simulators, drove the development of new graphics technologies. One key area was the simulation of natural landforms, vegetation, seascapes, and other environmental features. Hitherto, the public perception of computer graphics (as represented in films such as "Tron" and "War Games") had been of vector 3D shapes and textured solid models. However, during the I980s, a new and increasingly ubiquitous image appeared: the "fractal," a word coined by Benoit Mandelbrot and visualized as the Mandelbrot set $[\mathrm{I}, 2]$. This radically changed the idea that computer graphics had to look artificial; along with other techniques, it raised the possibility of simulating the natural world. Mandelbrot himself referred to the collision of abstraction and naturalism that occurred when fractals were first used by Richard Voss and others to generate landscapes:
Nicholas Lambert

Department of History of Art,

Film and Visual Media

Birkbeck College

University of London

United Kingdom

n.lambert@bbk.ac.uk

William Latham

Goldsmiths College

University of London

United Kingdom

w.latham@gold.ac.uk

Frederic Fol Leymarie

Goldsmiths College

University Of London

United Kingdom

f.leymarie@gold.ac.uk 
What a profound irony that this new geometry, which everyone seems spontaneously to describe as "baroque" and "organic", should owe its birth to an unexpected but profound new match between those two symbols of the inhuman, the dry, and the technical: namely, between mathematics and the computer [3].

Such a possibility had actually been raised back in the early 1950s by Alan Turing himself [4]. Fascinated as he was by the symmetries and structures produced by organisms, he realized he could investigate the area of morphogenesis using the new Ferranti computer. Unfortunately, his death occurred in the middle of this ground-breaking work, and his thoughts on evolutionary systems cannot be deduced from his surviving notes. Yet he pre-empted a whole area of biological and genetic research in the I980s that was also preceded by John Conway's Game of Life [5].

It was The Blind Watchmaker by biologist Richard Dawkins that inspired the first true flourishing of artificial life (A-Life) in the computational medium, and crucially gave rise to a number of aesthetic innovations [6]. Dawkins named the new emergent forms after the surrealist paintings made by Desmond Morris that contained "vaguely animal-like shapes," which Morris described as "biomorphs" [7]. Dawkins created genetic rules for each tree that enabled them to mutate as different lineages were bred together. He made the tree-like forms symmetrical about their vertical axis for reasons of parsimony and aesthetics, as well as "because [he] was hoping to evolve animal-like shapes, and most animal bodies are pretty symmetrical” [8].

Dawkins noted that despite experimenting with other growth patterns, the symmetrical plan generated the most interesting, and indeed "lifelike," results. This was a lucky outcome, but later Dawkins deliberately added genes to control the segmentation of the forms, mirroring the importance of segmented bodies in the animal kingdom [9]. With segmentation and symmetry combined, the resulting forms had the greatest diversity and therefore "fitness." Yet the original decision was fortuitous, and the outcomes truly emergent.

It would seem that both Dawkins and Mandelbrot, though scientists by training and vocation, were well aware of the aesthetic potentials of their discoveries. In Mandelbrot's case, the similarities with natural forms were striking and obvious, especially after they were applied to textures and landscapes in 3D programs by Alan Norton and others [Io]. However, Dawkins' evolutionary forms would encounter the work of an artist already immersed in the concepts of mutation and generation.

\section{The Early Computer Artworks of William Latham}

William Latham started working with computers in 1985 after completing his MA degree in fine art at The Royal College of Art in London. At an early stage in his career, he took the concept of evolving forms and freely developed it into a distinctive artistic style, which incorporates natural and artificial elements. Latham is also interesting for having gradually moved away from art in 1993 and into computer games, which incorporate ideas and code taken from his earlier art work.

Latham was interested in the evolution of form even before he discovered computing. "During the period 1983 to 1985 , using a set of rules, he designed and termed "FormSynth," for the transformation of shapes, he set out to sketch huge drawings of multiplying, changing forms (Figure I).

The logic and consistency of Latham's possible worlds arises from his concept of an evolutionary approach to the making of sculpture. The complexity and vitality of the forms he devised is 


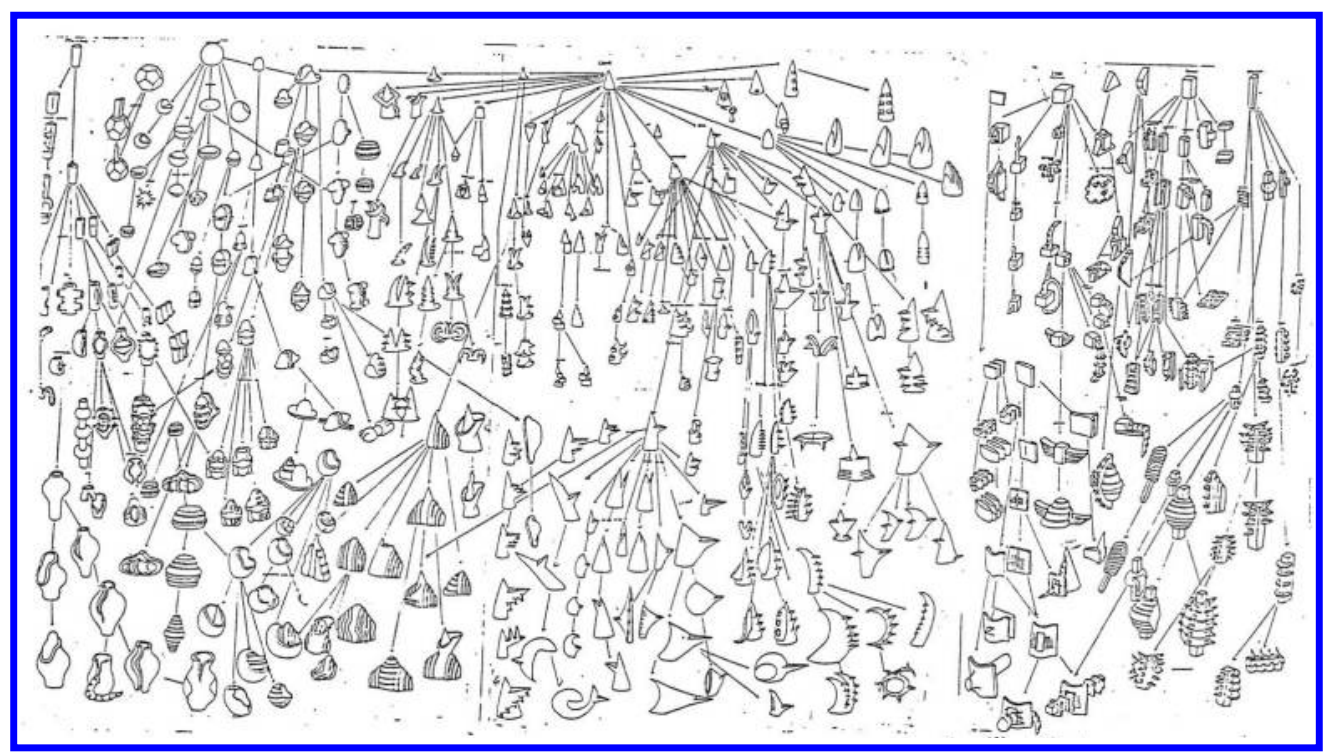

Figure 1. FormSynth evolutionary drawing, William Latham. 1983-85. Details of a two-meter, hand-drawn FormSynth tree. ( ) 1983-85 William Latham.

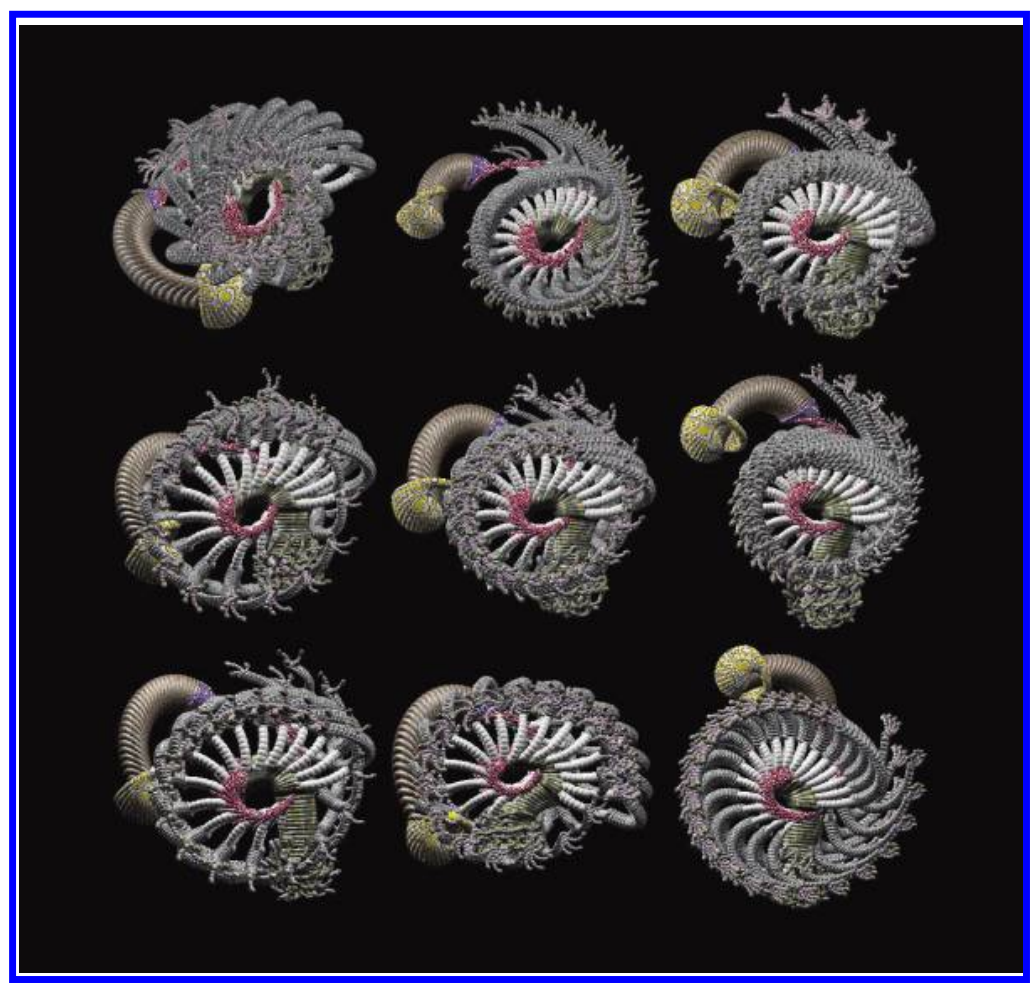

Figure 2. FormGrow/Mutator Generated Art, 1989. Nine mutations (ribbed branched structures), evolved forms resulting from the use of a Mutator session within FormGrow. @ 1989 William Latham.

derived from the step-by-step accretion of "operations" on simple initial forms such as cones, spheres, or tori [II].

John Lansdown, in his introduction to "The Conquest of Form", Latham's 1989 exhibition at the Arnolfini in Bristol, UK, considered that Latham and others working with him (in particular Stephen Todd and Mike King) were exponents of "another form of sculpture" [I2]. This is derived from the illusory yet real appearance of these works: their seeming materiality is defeated by the obvious departures from our physical reality (Figure 2). Even this system could produce unexpected results $\left[\mathrm{I}_{3}\right]$. 
In 1987, Latham was appointed artist and research Fellow at IBM's UK Research Labs in Winchester, where he began working with mathematician and programmer Stephen Todd on a system called FormGrow. This built on FormSynth and allowed simple construction rules such as bulging and hollowing objects. As he worked with this system, building up a new library of rules, Latham realized that some of his long repeated sequences of FormSynth operations could be condensed into new rules, such as those for growing tendrils and horns.

Later on, by the end of 1988, Latham and Todd started using an "add on" new system they developed, called Mutator, that managed the data from FormGrow and began to cross-breed forms together, by identifying their basic components as "genes" and allowing these to be recombined and modified to produce large evolutionary trees of computer-generated imaginative $3 \mathrm{D}$ forms (Figure 2). As Latham says: "Mutator derives its methods from processes of nature, and was partly inspired by a simulation of natural selection" [I4]. Importantly, the Mutator system enabled the artist to pick, breed, and marry natural-looking forms at will based on their aesthetic quality, which gave the artist a highly intuitive and minimal interface.

This system has an overall appearance that could be called "organic" and seemingly aims toward natural yet fantastical forms. Latham's stylistic decision on which operations to use was made at the level of the core design of the program itself, ensuring that all images bear his imprint, to a degree. The aesthetic of these images, while inspired by nature and science-fiction, remains very much their own. These are forms that would have been inconceivable without the computer to perform all the millions of possible changes, transformations and developments that Latham foresaw (Figure 3).

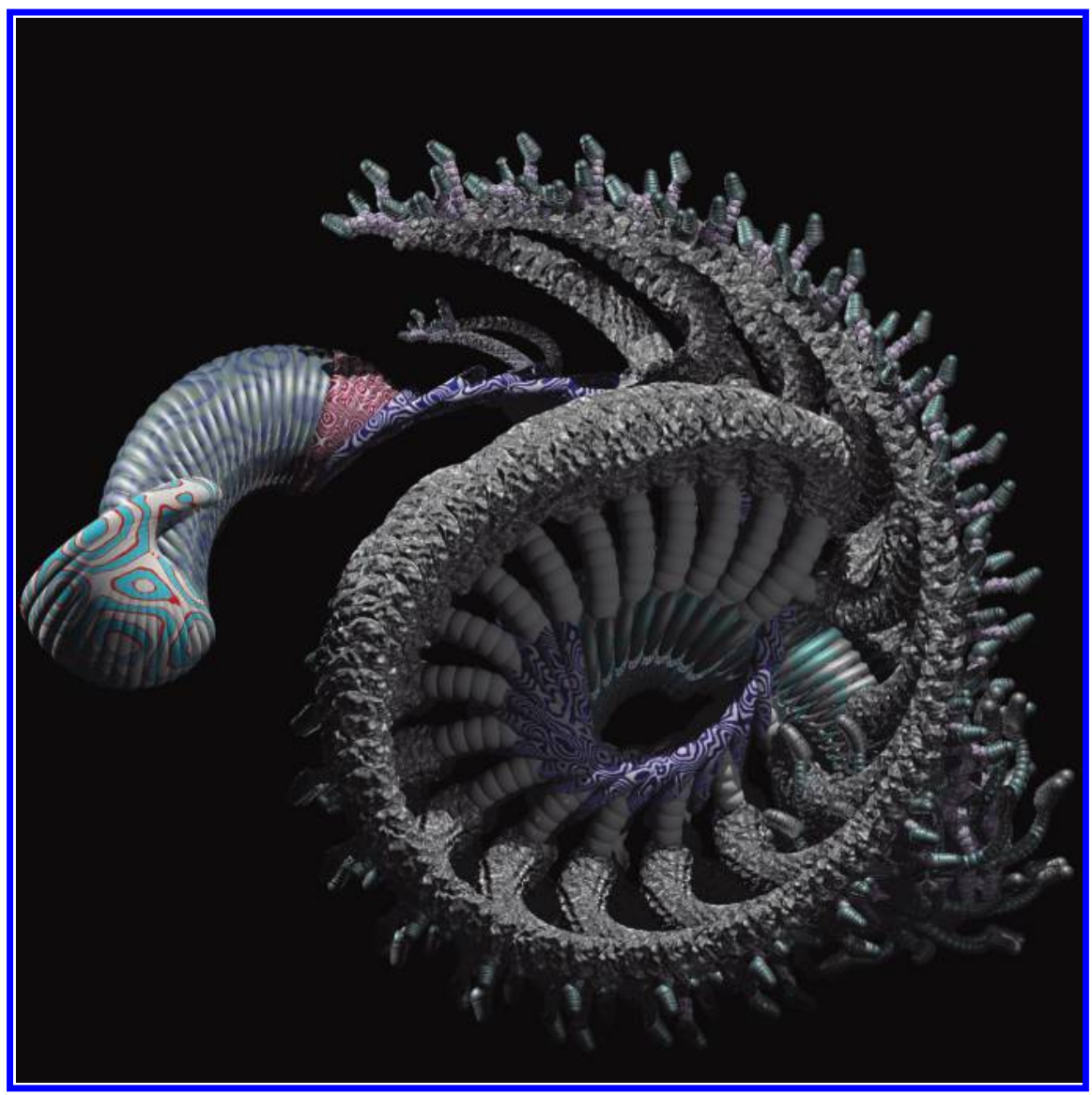

Figure 3. Mutation X. Raytraced. 1989. Final evolved form resulting from a Mutator session. () 1989 William Latham. 
One might justifiably question the artist's role in images that are not merely assembled by the computer in its capacity as a tool, but generated directly by it. Where is the human input? Latham counters that his input is at the level of the software itself, which imparts not only the formal construction of the objects but also more intangible aspects of their style as well. Latham's major influences are science-fiction imagery-one is reminded especially of H.R. Giger's designs for the "Alien" films [I5] and the seminal book On Growth and Form by biologist D'Arcy Thompson, which revealed the mathematical structure underpinning the shapes of life forms [16]. By shaping the code that in turn creates the images, Latham's involvement is at the conceptual rather than practically artistic level, though he also exercises further artistic judgment in choosing certain paths for his images to grow and develop, and their final visual quality in terms of color and texture.

\section{Karl Sims and Artificial Life}

Although Richard Dawkins had given impetus to simulations of evolution, it was not until Dawkins himself introduced his "Biomorphs" that a number of major figures in this emerging area, including Karl Sims, began developing their own concepts [I7].

From this, Sims developed a program that used the basic genetic concepts of selection, reproduction, and sexual combination to evolve an artificial genotype, and in so doing represent the Darwinian idea of "fitness" in action (Figure 4).

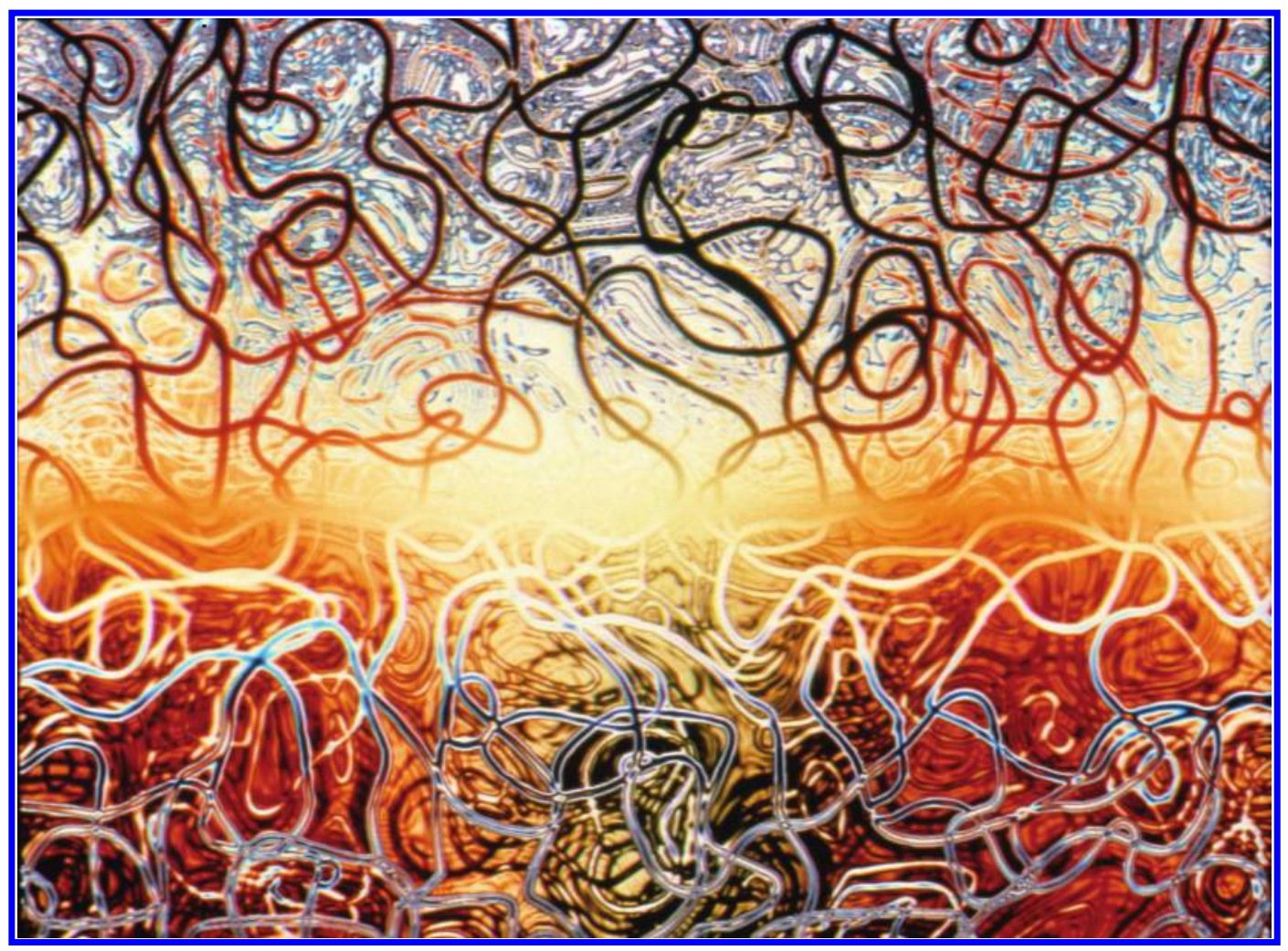

Figure 4. Extinct Image, Karl Sims, 1990. From “Artificial Evolution for Computer Graphics," ACM SIGGRAPH '91 Conference Proceedings, Las Vegas, Nevada, July 1991 (c) Karl Sims.

"A-Life, then, is fundamentally concerned with understanding and formalizing the underlying dynamic structures of living things" [18]. A-Life art, defined in the simple sense outlined above, engages with the same ideas: it is a form of art practice that begins to take on, in various ways, the abstract dynamics of nature. 
In terms of the creative process, both Sims and Latham primarily use the human as a cost function in a Monte Carlo-type simulation to explore a multi-dimensional parameter space in which the unevenness of parameter space is covered. Interestingly, during this period, the use of constraints played a small role, apart from individual mutate-able parameters with maximum and minimum values and the implicit constraints of Sims' Lisp Code and Latham's FormGrow logic. In addition, the automatic culling of generated forms (based on mathematical criteria) to reduce the size of the search space was limited. Replacing the artist (as a fitness function selector) was also very limited.

In his 200I essay that considers the origins of A-Life and art, Mitchell Whitelaw points to a 1987 seminar by Christopher Langton in Los Angeles as the starting point for this area. Looking for precedents in art for the concept of artificial biology, he points to Goethe's analogies between living creatures and works of art, and Klee's understanding of his "picture plane as a kind of contained, artificial world" [I9].

Whitelaw also points to Kasimir Malevich's Suprematism, which, although it renounced realistic and imitative painting, viewed the pictorial image as an object in its own right: "a work of pure, living art," as Malevich put it. Malevich also considered a machine to be a "technical organism" and used similar biological metaphors for technology [20].

\section{An Evolutionary Aesthetic?}

Do new aesthetic forms in digital art depend on an understanding of the software and programming? Latham, of course, worked extensively with programmers, but he arrived at the computer with a strong sense of process in art. His evolutionary sketches show a means of deploying form in an evolutionary methodology. Because he had been interested in evolving forms even before he used computers, he was able to apply the most distinctive computer quality of all: the modelling of dynamic processes.

These artistic systems are not wholly deterministic, running an image through pre-set parameters until it reaches perfection. Indeed, Latham realized early on that the most interesting outcomes of his program were quite unforeseen by him: his evolutionary program could arrive at unexpected conclusions. Even if an artist programs the computer from the start, there will always be an important element of mystery in the working of the software.

Such quirks render the computer less mechanistic (and predictable) and more "artistic," because the outcome of certain operations cannot always be foreseen. This unpredictability can be harnessed in the same way as the chemical reactions of pigments, or the densities of stone. In other words, an artist develops a feel for its working and gradually incorporates its idiosyncrasies into their work, which itself changes subtly or overtly to accommodate these properties.

This is evident in FormSynth and Mutator, where Latham's choice of operations performed on the initial shapes guided their eventual appearance. Latham's stylistic involvement was, in a sense, pre-visual; it affected the starting point and development of all images generated through the program rather than just a single artwork. Although he modified of the program's underlying code, there were visual consequences because in this way Latham determined the visual environment in which his shapes could develop. Latham compared the artist to a gardener who guides the growth of a plant but is not the source of its life. This is itself a new development for art $[2 \mathrm{I}]$. 
Mitchell Whitelaw sees in this a factor that is identified in a more general sense as the artist's "signature" or style, because the "formal vocabulary of elements and transformations" that takes place in Latham's work gives it a distinctive visual form. However from a purely exploratory, even scientific, perspective in terms of A-Life, it is also a limitation. The selection Latham exercises is primarily an aesthetic one that gives a "non-natural" aspect to the genetics of his work [22].

Latham's Organic Art images are the product of evolutionary processes and thus indirect products of his artistic vision. They are "indirect" in the sense that Latham developed the program to evolve shapes along particular visual lines, but its continued operation is not dependent on his intervention. Like Harold Cohen's AARON simulated painting program [23], the widely distributed Organic Art software could continue to create Lathamesque images long after his demise, with varying inputs and changes from computer users. The encoding of his evolutionary process in software allowed him to make it portable and then distribute it widely as digital code. Again, this widely distributed software may produce images not directly conceived by the artist, but the images will be inherent within the parameters of the software. Latham is responsible for assembling these elements according to his vision and requirements, but the final image is the result of the software's own working through these possibilities.

Unlike AARON, however, with its complex relation to Cohen's creative input, Latham's software has a straightforward input procedure and generates images from his initial input parameters. AARON is not so straightforwardly instructed; it seemingly derives its own decisions about what to draw from its understanding of art.

There are two different forces at work here. Firstly, there is the artist's control exercised by writing or mastering the appropriate software to create images. Secondly, there is the serendipitous aspect of accidental discovery inherent in an open-ended program where absolute control yields to experimentation and chance discoveries. In Latham's work, the evolutionary nature is the result of a programmer's control in setting up the initial conditions, then exercising further choice over the outcomes of these experiments. A fascination with growth and artificial, yet naturalistic, forms is essential to his art. 


\section{Conclusion}

The period from 1980 to 1993 was initially dominated by fractal art led by Benoit Mandelbrot, followed by radical developments in evolutionary art as the impact of mutation systems such as Dawkins' Biomorphs gained momentum with a number of key evolutionary art figures such as Karl Sims and the Latham-Todd tandem, whose work was shown extensively at SIGGRAPH during the period from the late I980s to the early 1990s. These evolutionary artists were able to define core rules for growth of computer graphic forms and then use a mutation system that enabled them to pick and breed purely based on aesthetics to rapidly explore vast areas of multidimensional parameter space, not knowing what they would discover. Importantly this work enabled highly intuitive and artist-friendly interfaces to be developed with the addition of cross-breeding to zoom in on pleasing emerging outcomes.

In parallel to this emergence of evolutionary art using computers, related work was being done through the 1980 os in other scientific and technological areas. In the area of perception and computer vision, Michael Leyton was, for example, exploring the representation of shapes as processes that transform them, generating a plausible causal explanation for their "history" [24], a concept very much akin to Latham's own thinking in his development of the FormSynth system. In the area of the computer simulation of plant development, the use of procedural graphics combined with rule-based L-systems was becoming mature, building from the early works of biologist Aristid Lindenmayer [25]. Also in parallel, rapid developments were occurring in evolutionary biology and genetics, in particular from 1990 with the launch of the Human Genome Project, while in more traditional visual art, strong influences of biology were also noticeable, for example in the works of Chadwick's viral landscapes, Hirst's animal dissections, and Borland's preoccupation with anatomy (Figure 5).

Though by the mid-r99os Sims and Latham had become involved in new commercially focussed projects outside computer art, the core themes and ideas were taken up by new groups of artists including Jon McCormack and Steven Rooke, and then extended further with the full emergence of the artificial life research field and associated conferences [26].

Becoming interested again in research, Latham moved back into academia in 2005 and became professor of computer art at Goldsmiths, University of London in 2007, where he collaborated with professor Frederic Fol Leymarie and worked again with Stephen Todd after a gap of 12 years. His recent work has included re-applying the old FormGrow and Mutator systems rewritten in Java and OpenGL to the world of genomics and scientific visualization in collaboration with the structural bioinformatics team at Imperial College London [27, 28]. 


\section{References}

I. Mandelbrot, Benoit, "Fractal Aspects of the Iteration of $\mathrm{z} \rightarrow \mathrm{Lz}(\mathrm{L}-\mathrm{z})$ for Complex $\mathrm{L}$ and $\mathrm{z}$," Annals of the New York Academy of Science, Vol. 357, 249-259 (1980).

2. Mandelbrot, Benoit, The Fractal Geometry of Nature (New York: W.H. Freeman, 1982).

3. Mandelbrot, Benoit, "Fractals and an Art for the Sake of Science," Leonardo Supplemental Issue, Vol. 2, Computer Art in Context: SIGGRAPH '89 Art Show Catalog, 2I-24 (1989).

4. Turing, Alan M., "The Chemical Basis of Morphogenesis," Philosophical Transactions of the Royal Society B, Vol. 237, No. 64I, 37-72 (1952).

5. Gardner, Martin, "Mathematical Games: The Fantastic Combinations of John Conway's New Solitaire Game 'Life'," Scientific American, Vol. 223, I20-I23 (1970).

6. Dawkins, Richard, The Blind Watchmaker (New York: Norton \& Co., 1986) 55.

7. Levy, Silvano, Desmond Morris: so Years of Surrealism (London: Barrie \& Jenkins, 1997).

8. Dawkins, Richard, The Blind Watchmaker (New York: Norton \& Co., 1986) 8.

9. Ibid., 329 .

Io. Norton, Alan, "Generation and Display of Geometric Fractals in 3-D," Computer Graphics, Vol. I6, No. 3 (1970).

II. Lansdown, John, "The Possible Worlds of William Latham," The Conquest of Form: Computer Art by William Latham, Arnolfini Gallery, Bristol, 3 December 1988-15 January 1989.

I2. Ibid.

I3. Todd, Stephen, and William Latham, Evolutionary Art and Computers (London: Academic Press, 1992) 2.

I4. Ibid.

I5. Giger, H.R., Giger's Alien (London: Big O Publishing, 1979).

16. Thompson, D'Arcy Wentworth, On Growth and Form (Cambridge: Cambridge Univ Press, 1917).

I7. Greenfield, Gary R., "Simulated Aesthetics and Evolving Artworks: A Coevolutionary Approach," Leonardo, Vol. 35, No. 3, 283-289 (2002).

18. Whitelaw, Mitchell, “The Abstract Organism: Towards a Prehistory for A-Life Art," Leonardo, Vol. 34, No. 4, 345-348 (200I).

I9. Ibid., 346.

2o. Ibid., 347 .

2I. Todd, Stephen, and William Latham, Evolutionary Art and Computers (London: Academic Press, I992) I2.

22. Whitelaw, Mitchell, “Tom Ray's Hammer: Emergence and Excess in A-Life Art," Leonardo, Vol. 3I, No. 5, 377-38I (1998).

23. McCorduck, Pamela, Meta-Art, Artificial Intelligence, and the Work of Harold Cohen (New York: W.H. Freeman, 199I).

24. Leyton, Michael, “A Process-Grammar for Shape," Artificial Intelligence, Vol. 34, No. 2, 213-247 (1988). 25. Prusinkiewicz, Przemyslaw, and Lindenmayer, Aristid, The Algorithmic Beauty of Plants (New York: Springer-Verlag, 1990).

26. Whitelaw, Mitchell, Metacreation: Art and Artificial Life (Cambridge, MA: MIT Press, 2004).

27. Latham, William, et al., "Using DNA to Generate 3 D Organic Art Forms," Evo'o8 Proceedings of the 2008 Conference on Applications of Evolutionary Computing (Berlin: Springer-Verlag, 2008) 433-442.

28. Latham, William, et al., "From DNA to 3 D Organic Art Forms," Proceedings SIGGRAPH 'o7 ACM SIGGRAPH 2007 Sketches (New York: ACM, 2007), accessed at <www.siggraph.org/s2007/attendees/ sketches/3.html>. 